\title{
Alcoholism and Its Role in the Development of Oxidative Stress and DNA Damage: An Insight
}

\author{
Sabitha Kandi ${ }^{1}$, Neelesh Deshpande ${ }^{2}$, Venkata Bharath Kumar Pinnelli ${ }^{3}$, Ramakrishna Devaki ${ }^{4}$, Pragna Rao $^{5}$, \\ K V Ramana ${ }^{6, *}$ \\ ${ }^{1}$ Department of Biochemistry, Chalmeda Anandarao Institute of Medical Sciences, Karimnagar, India \\ ${ }^{2}$ Department of Biochemistry, Government Medical College, Nagpur, India \\ ${ }^{3}$ Department of Bio-chemistry, Vaidehi Institute of Medical Sciences, and Research Centre, Bangalore, India \\ ${ }^{4}$ Department of Biochemistry, Kamineni Institute of Medical Sciences, Narketpally, India \\ ${ }^{5}$ Department of Biochemistry, Kasturba Medical College, Manipal University, Manipal, India \\ ${ }^{6}$ Department of Microbiology, Prathima Institute of Medical Sciences, Karimnagar, India \\ *Corresponding author: ramana_20021@rediffmail.com
}

Received June 23, 2014; Revised July 10, 2014; Accepted July 14, 2014

\begin{abstract}
Alcohol is detoxified in the liver by the enzymes alcohol dehydrogenase and aldehyde dehydrogenase. The available literature suggests that activity of aldehyde dehydrogenase is less than alcohol dehydrogenase among Asians; hence it leads to accumulation of acetaldehyde during excess intake of alcohol. Accumulated acetaldehyde due to its electrophilic nature forms adducts with proteins and DNA. The acetaldehyde-DNA adduct (N-2-Ethyl deoxyguanosine (NDG)) induces mutations in DNA and leads to DNA damage. Prevention of excessive accumulation of acetaldehyde can be useful in decreasing the genotoxicity.
\end{abstract}

Keywords: alcoholism, alcohol dehydrogenase, aldehyde dehydrogenase, N-2-Ethyl deoxyguanosine (NDG), oxidative stress

Cite This Article: Sabitha Kandi, Neelesh Deshpande, Venkata Bharath Kumar Pinnelli, Ramakrishna Devaki, Pragna Rao, and K V Ramana, "Alcoholism and Its Role in the Development of Oxidative Stress and DNA Damage: An Insight.” American Journal of Medical Sciences and Medicine, vol. 2, no. 3 (2014): 64-66. doi: 10.12691/ajmsm-2-3-3.

\section{Introduction}

\subsection{Alcohol Metabolism}

Alcohol is detoxified and eliminated in the liver via series of oxidative reactions [1,2]

Alcohol dehydrogenase Aldehyde dehydrogenase $\mathrm{C}_{2} \mathrm{H}_{5} \mathrm{OH}$
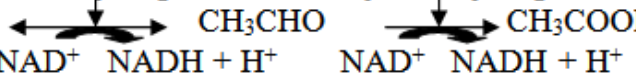

$\longrightarrow \mathrm{CO}_{2}+\mathrm{H}_{2} \mathrm{O}$

Alcohol dehydrogenase (ALD) has high affinity for alcohol [3] and breakdown ethanol in the cytoplasm. The ethanol oxidation is also mediated by catalase enzyme in microsomes [4,5]. The oxidation of acetaldehyde is carried out by mitochondrial aldehyde dehydrogenase (Ald.dh). This step is also catalysed by cyt. P450 E1 (CYP2E1) through NADPH dependent pathway [6]. The acetate is further spontaneously broken down to $\mathrm{CO}_{2}$ and water. When alcohol entry is more the acetaldehyde accumulated and exerts its effects as the first step is reversible reaction. The activity of ALD is more than aldehyde dehydrogenase so, acetaldehyde accumulates in liver. Aldehyde is toxic, which in excess leads to cell death. Acetaldehyde can produce adducts with proteins like amino acids, sulfhydryl groups and other components like nucleotides, phospholipids. Free radicals like hydroxyl ethyl radicals can produce irreversible liver damage [7].

The oxidation of alcohol by ALD and Ald.dh both leads to high NADH/NAD+ ratio. It leads to

- Lacticacidosis- Increased NADH leads to conversion of Pyruvate to lactate.

- Hypoglycemia- Deficiency of pyruvate leads to decreased availability of oxaloacetate(OAA), decreases gluconeogenesis.

- Ketogenesis- Decreased pyruvate, increases OAA, decreases TCA cycle, Increased NADH/NAD+ ratio causes more accumulation of acetyl-coA, thus increases ketogenesis

- Fatty liver- Increased acetyl-coA, Increases Fattyacid synthesis, Increases TAG formation

- Increases ROS generation- Damage mitochondria, apoptosis

- Increased Lactate- Decreases uric acid excretion leads to Gout

- CNS depression- Increased synthesis of GABA(Gamma Amino Butyric Acid)

\section{Alcohol \& Oxidative Stress}


Alcohol when consumed in limited amounts $(<70 \mathrm{ml} /$ day) will not cause any deleterious effect on liver. But in excess leads to fibrotic changes in liver, as liver cannot metabolize alcohol beyond a specific threshold level [8]. Oxidative stress (OS) is defined as an imbalance between pro-oxidant and anti-oxidant mechanisms in human where the balance is towards the former [9]. The increased consumption of alcohol leads to production of reactive oxygen species (ROS). High levels of ROS results in oxidative stress which causes severe malfunction and damage to biological macromolecules [10]. Severe OS decreases antioxidant substances like Glutathione, thus can cause cell damage, can trigger apoptosis while more intense conditions may lead to necrosis of tissue concerned [11]. The lipid peroxidation product, malondialdehyde (MDA), stimulates directly or indirectly the lipocytes resulting in liver fibrosis $[12,13,14]$. It has been observed that chronic ethanol exposure increases iron load $[15,16]$. Here ethanol increases lipid peroxidation with iron acting as a cofactor in catalyzing lipid peroxidation and is responsible for increased MDA levels $[17,18]$.

\section{Alcohol \& DNA Damage}

Excess alcohol consumption causes accumulation of acetaldehyde. The accumulated acetaldehyde causes DNA damage and activates FA - BRCA network in liveror breast cells [19]. The electrophilic nature of acetaldehyde enables it to bind and form adducts with proteins, lipids and DNA [20,21,22,23,24]. The acetaldehyde derived DNA adducts like N2 ethyl deoxy guanosine (NDG) has ability for cross linking, which leads to chromosomal abnormalities. Thus, NDG can be used as a biomarker of acetaldehyde induced DNA damage [25]. Acetaldehyde adducts contribute to injury, degeneration, carcinogenesis and play an important role in pathogenesis of liver disease [26]. Alcohol mediates its mutagenic effects by formation of acetaldehyde adducts, increases oxidative stress, enhances the activity of kupffer cells by increasing production of gut derived endotoxins and also release tumor necrosis factor alpha (TNF- $\alpha)$, inhibits DNA methylation, impairs retinoid metabolism, which is important for cell proliferation [27].

Alcoholism causes accumulation of acetaldehyde which results in genotoxicity. The changes that occur due to accumulated acetaldehyde is similar to the changes seen during hepatocellular carcinoma [28,29,30,31].

\section{Conclusion}

Alcoholism increases the production of ROS, oxidative stress and results in the accumulation acetaldehyde. The electrophilic nature of acetaldehyde makes it to form adducts with DNA such as N2 ethyl deoxy guanosine (NDG). This NDG can be used as biomarker for acetaldehyde induced DNA damage. Thus, alcoholism leads to oxidative stress which in turn causes mutation in DNA, impairs cell proliferation and thus, preventing accumulation of acetaldehyde can be helpful to decrease the genotoxicity.

\section{References}

[1] Thiele GM, Klassen LW, Tuma DJ. Formation and immunological properties of aldehyde-derived protein adducts following alcohol consumption methods. Mol. Biol. 2008; 447: 235-257.

[2] Tuma DJ, Casey CA. Dangerous byproducts of alcohol breakdown focus on adducts. Alcohol Res Health. 2003: 27: 285-290.

[3] Free man Tl, tuma DJ, Thiele GM, Klassen LW, Worrall S, et al., Recent advances in alcohol - induced adduct formation. Alcohol Clin Exp Res. 2005; 29: 1310-1316.

[4] Barry RE, Williams AJ. Metabolism of ethanol and its consequences for the liver and gastrointestinal tract. Dig Dis. 1998; 6: 194-202.

[5] Crabb DW, Liang punsakul S. Acetaldehyde generating enzyme systems: role of alcohol dehydrogenase, CYP2E1 and catalase, and speculations on the role of other enzymes and processes. Novartis Found Symp. 2007; 285; 2-16.

[6] Kunitoh S, Imaoka S, Hiroi T, Yabusaki Y, Monna T, Funae Y. Acetaldehyde as well as ethanol is metabolized by human CYP2E1. J Pharmacol Exp Ther. 1997; 280: 527-532.

[7] DM Vasudevan, Sree Kumari S, Kannan Vaidyanathan. Metabolic pathways of other carbohydrates. Chapter 11. Text book of Biochemistry for medical students; $7^{\text {th }}$ edition; Jaypee brothers Medical Publishers (P) Ltd. 2013; Pg140.

[8] Savolainen V T, Liesto K, Mannikko A, Penttila A and Karhuna P J. Alcohol consumption and alcoholic liver disease: Evidence of a threshole level of effects of ethanol. Alcoholism: Clinical and Experimental Research. 1993; 17: 112-1117.

[9] Halliwell B, Gutteridge JMC, Cross CE. Free radicals, antioxidants and human disease; where are we now? J Lab Clin Med. 1992; 598-620.

[10] Kandi Sabitha, B. Venugopal, Md Rafi, KV Ramana. Role of antioxidant enzymes in glucose and lipid metabolism in association with obesity and type2 diabetes. American Journal of medical sciences and Medicine 2014; vol.2, No. 1; 21-24.

[11] Nalini G, Hariprasad C and Narayana VA. Oxidative stress in alcoholic liver disease. Indian J Med Res. 1999; 110; 200-3.

[12] Friedman SL. 1999. The cellular basis of hepatic fibrosis. Mechanism and treatment strategies N Engl J Med. 1999, 328; 1828-35.

[13] Svegliati - Baroni G, Di Sario A, Ferretti G, D’Ambrosio L,et.al., The $\mathrm{Na} / \mathrm{H}$ exchanger modulates the fibrogenic effect of oxidative stress in rat hepatic stelleate cells. J Hepatol. 1999; 30: 868-75.

[14] Sukamato H.C, Kim W, Louz Z, Horn W, Sul C. Role of lipid peroxidation in vitro and in vivo models of liver fibrogenesis. Gastroenterology, 1993, 104: 1012.

[15] Bruce BR, Anthony ST, Gary MB, Park CH and Richard OR. Hepatic lipid peroxidation in vivo in rats with chronic iron overload. J Clin. Invest, 1983; 17; 429-439.

[16] Kukielka E, Cederbaum AI The effect of chronic ethanol consumption on NADH- and NADPH-dependent generation of reactive oxygen intermediates by isolated rat liver nuclei. Alcohol Alcohol 1992; 27:233-239.

[17] Harrison - Findik DD. Role of alcohol in the regulation of iron metabolism. World J Gastroenterol. 2007; 13(37); 4925-4930.

[18] Neelesh Deshpande, sabitha Kandi, P.venkata Bharath Kumar, KV Ramana, Manohar muddeshwar. Effect of alcohol consumption on oxidative stress markers and its role in the pathogenesis and progression of liver cirrhosis. American Journal Of medical \& Biological research, 2013; 1(4); 99-102.

[19] Jessy Abraham, Silvia Balbo, David Crabb \& Philip J Brooks. Alcohol metabolism in human cells cause DNA damage and activates Fanconi Anemia - breast cancer suspectability (FA _ BRCA) DNA damage response network. Alcoholism: Clinical \& Experimental Research, 2011.

[20] Seitz HK, Becker P. Alcohol metabolism and cancer risk. Alcohol Res health. 2007; 30: 38-41. 4-7.

[21] Tuma DJ, Casey CA. Dangerous by products of alcohol breakdown - focus on adducts. Alcohol Res Halth. 2003; 27: 25290.

[22] Freeman TL, Tuma DJ, Thiele GM, Klassen LW, Wrrall S et. al., Recent advances in alcohol - induced adduct formation. Alcohol Clin Exp Res. 2005; 29:1310-1316.

[23] Brooks PJ, Theruvathu JA. DNA adducts from acetaldehyde: implications for alcohol - related carcinogenesis. Alcohol. 2005; 535: 187-93. 
[24] Tuma DJ. Role of MDA - acetaldehyde adducts in liver injury. Free Radic Biol Med. 2002; 32: 303-308.

[25] Fang JL, Vaca CE. Detection of DNA adducts of acetaldehyde in peripheral WBC's of alcohol abusers. Carcinogenesis. 1997; 18: 627-32.

[26] Mayans MV, Calvet X, Bruix J, Bruguera M, Costa J et al., Risk factors for hepatocellular carcinoma in catalonia, Spain. Int J Cancer. 1990; 46: 378-381.

[27] Chuang SC, La Veechia C, Boffetta P. Liver cancer: descriptive epidemiology and risk factors other than HBV and HCV infection. Cancer Lett. 2009; 286-9-14.
[28] Singh NP, McCoy MT, Tice RR at al., A simple technique for quantitation of low levels of DNA damage in individual cells. Experimental Cell Research. 1988; 175: 184-191.

[29] Tsukamoto H, Lu SC. Current concepts in the pathogenesis of alcoholic liver injury. FASEB J. 2001; 15: 1335-49.

[30] Wang Y, Millonig G, Nair J, Patsenker E, Stickel F et al., Ethanol - induced cytochrome P450 2E1 causes etheno - DNA lesions in alcoholic liver disease. Hepatology; 2009: 50: 453-461.

[31] Neelesh Deshpande, Sabitha Kandi, Manohar Muddeshwar, K V Ramana. Effect of alcohol consumption and oxidative stress and its role in DNA damage. American Journal of Biomedical research, 2014, vol.2, No.1, 7-10 